\title{
Metabolic and electrolyte abnormalities during heat exhaustion
}

\author{
Aijaz Ahmed, Ara Sadaniantz
}

An 81-year-old man, resident of a poorly ventilated, ineffectively air-conditioned inner city apartment, presented during a heat wave (environmental temperature $80^{\circ}-93^{\circ} \mathrm{F}$ and humidity $70 \%-80 \%$ ) with hyperthermia, confusion and dehydration. The patient had mild hypertension, depression and urinary incontinence and was taking hydrochlorothiazide/methyldopa, nortriptyline and oxybutynin.

On admission, tympanic temperature was $39.4^{\circ} \mathrm{C}$, pulse rate 124 beats $/ \mathrm{min}$, respiration 24 breaths/min and blood pressure $156 / 86 \mathrm{mmHg}$. On initial examination lung fields were clear, the patient had a holosystolic murmur, and central nervous system examination was unremarkable except for confusion. Dehydration was characterised by haemoglobin $19.7 \mathrm{~g} / \mathrm{dl}$, haematocrit $53.9 \%$, blood urea nitrogen $12.5 \mathrm{mmol} / \mathrm{l}$ and creatinine $141.4 \mu \mathrm{mol} / \mathrm{l}$. Serum electrolytes were: sodium $133 \mathrm{mmol} / 1$, potassium $2.9 \mathrm{mmol} / \mathrm{l}$ and phosphate $0.5 \mathrm{mmol} / 1$. Arterial blood gas analysis (pH 7.5, $\mathrm{pCO}_{2} 40 \mathrm{mmHg}, \mathrm{pO}_{2} 62 \mathrm{mmHg}$ and $\mathrm{HCO}_{3} 31 \mathrm{mmol} / \mathrm{l}$ ) was consistent with metabolic alkalosis. Serial electrocardiograms showed anterior $\mathrm{T}$-wave evolution consistent with myocardial injury. An initial creatine phosphokinase (CPK) level of 4234 IU peaked to $32800 \mathrm{IU}$; CPK-MB isoenzyme was also elevated to $43.3 \mathrm{ng} / \mathrm{ml}$ and $\mathrm{MB}$ index was $0.1 \%$. Chest X-ray and computed tomography (CT) scan of the head were unremarkable. Echocardiogram showed severe mitral regurgitation and moderately reduced left ventricular function with apical akinesis. Blood, urine and sputum cultures failed to reveal a source of infection. The patient was admitted to the coronary care unit; hyperthermia was initially managed with cold sponging which resulted in a temperature drop from $39.4^{\circ} \mathrm{C}$ to $37^{\circ} \mathrm{C}$ in four hours. The patient's mental status improved and electrolytes were corrected (table). On day 5, he was transferred to a medical ward and discharged home on day 10 in a stable condition.

Table Changes in electrolytes and other blood chemistries during the five days in the coronary care unit

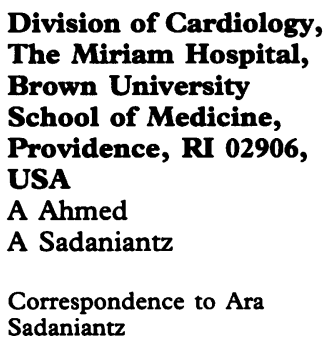
Sadaniantz

Accepted 27 September 1995

\begin{tabular}{lllllllll}
\hline & $\begin{array}{l}\text { Blood urea } \\
\text { nitroger } \\
(\mathrm{mmol} / \mathrm{l})\end{array}$ & $\begin{array}{l}\text { Creatinine } \\
(\mu \mathrm{mol} / \mathrm{l})\end{array}$ & $\begin{array}{l}\text { Sodium } \\
(\mathrm{mmol} / \mathrm{l})\end{array}$ & $\begin{array}{l}\text { Potassium } \\
(\mathrm{mmol} / \mathrm{l})\end{array}$ & $\begin{array}{l}\text { Chloride } \\
(\mathrm{mmol} / \mathrm{l})\end{array}$ & $\begin{array}{l}\mathrm{CO}_{2} \\
(\mathrm{mmol} / \mathrm{l})\end{array}$ & $\begin{array}{l}\text { Phosphate } \\
(\mathrm{mmol} / \mathrm{l})\end{array}$ & $\begin{array}{l}\text { Calcium } \\
(\mathrm{mmol} / \mathrm{l})\end{array}$ \\
\hline Normal values & $2.9-6.4$ & $62-124$ & $135-145$ & $3.5-5.2$ & $98-108$ & $23-33$ & $0.8-1.4$ & $2.25-2.62$ \\
Day 1 & 12.5 & 141.4 & 133 & 2.9 & 87 & 29 & 0.5 & 2.4 \\
Day 2 & 10.0 & 106.1 & 127 & 3.1 & 85 & 32 & 1.0 & 1.9 \\
Day 3 & 8.6 & 106.1 & 131 & 3.4 & 89 & 31 & 0.9 & 1.9 \\
Day 4 & 8.9 & 106.1 & 133 & 3.6 & 92 & 30 & 1.0 & 2.0 \\
Day 5 & 10.0 & 97.2 & 133 & 3.7 & 95 & 26 & 1.0 & 2.0 \\
\hline
\end{tabular}

\section{Questions}

1 What is the relationship between alkalosis and hypophosphatemia during heat exhaustion?

2 What was the cause of metabolic alkalosis in this case?

3 Is hypokalemia a predisposing factor to heat exhaustion and ensuing muscle (cardiac and skeletal) injury?

4 Did the medications taken by the patient predispose him to heat exhaustion? 


\section{Answers}

\section{QUESTION 1}

Severe heat exhaustion can be associated with hypophosphatemia. ${ }^{1}$ The increased cellular uptake of phosphorous secondary to alkalinisation probably results from increased phosphofructokinase activity. Phosphofructokinase is extremely sensitive to changes in $\mathrm{pH}$; its activity increases with a rise in $\mathrm{pH}$ resulting in cellular uptake of phosphorous and formation of phosphorylated glycolytic intermediates.

Hypophosphatemia is generally observed within hours after onset and undergoes spontaneous correction on the second or third day. The patient in this report had a phosphate level of $0.5 \mathrm{mmol} / 1$ on admission and $1.0 \mathrm{mmol} / 1$ the next day. Respiratory alkalosis is common in patients with heat exhaustion ${ }^{2}$ and may result in hypophosphatemia. ${ }^{3}$ In a study including 21 patients, ${ }^{4}$ the metabolic and respiratory changes during heat exhaustion were studied in subjects taking a variety of medications on admission; arterial blood gas analysis showed none of the patients to have metabolic alkalosis.

\section{QUESTION 2}

The metabolic alkalosis in this report can be explained by hypokalemia and contraction alkalosis. Hypokalemia results in movement of potassium out of the cells; this triggers hydrogen ion to move intracellularly to preserve electroneutrality, thus causing metabolic alkalosis. This patient used hydrochlorothiazide to control hypertension. It has previously been reported that thiazide-induced hypokalemia can result in metabolic alkalosis. ${ }^{5}$

\section{QUESTION 3}

An association between hypokalemia and enhanced susceptibility to heat stroke has not been proven in humans; however, experimental data suggest that such a relationship exists. ${ }^{6}$ Hypokalemia depresses glycogen synthesis in skeletal muscle. ${ }^{7,8}$ The decrease in glycogen stores during heat exhaustion predisposes the subject to rhabdomyolysis. Potassium is a potent vasodilator and enhances blood flow to the musculature during activity. ${ }^{9}$ Myocardial ischaemia is common during heat exhaustion $^{10}$; characteristically, subendocardial haemorrhages occur beneath the left interven-

1 Knochel JP, Caskey JH. The mechanism of hypophosphatemia in acute heat stroke. $\mathscr{f} A M A$ 1977; 238: 425-6. 2 Boyd AE. Beller GA. Heat exhaustion and respiratory alkalosis. Ann Intern Med 1975; 83: 835.

3 Coburn JW, Reba RC, Craig FN. Effect of potassium depletion on response to acute heat exposure in unacclimatized man. Am f Physiol 1966; 211: 117-24.

4 Sprung CL, Porto Carrero CJ, Fernaine AV, Weinberg PF. The metabolic and respiratory alterations of heat stroke. Arch Intern Med 1980; 140: 665-9.

5 Knochel JP. Heat stroke and related heat stress disorders. Disease-A-Month 1989; May: 305-77.

6 Hubbard RW, Mager M, Bowers WD, et al. Effect of low potassium diet on rat exercise hyperthermia and heat stroke potassium diet on rat exercise hyperthermi tricular septum. ${ }^{5}$ Hence, hypokalemia associated with heat exhaustion can cause rhabdomyolysis and myocardial infarction. The CPK-MB isoenzyme elevation can be explained by rhabdomyolysis but does not 0 exclude myocardial damage; up to $5 \%$ of total $\%$ CPK activity in skeletal muscle may be of CPK-MB isoenzyme moiety. ${ }^{5}$

\section{OUESTION 4}

Nortriptyline and oxybutynin have anticholi- $\stackrel{.}{.}$ nergic activities and may compound the $\overrightarrow{\bar{s}}$ effects of heat exhaustion by preventing heat $\overrightarrow{0}$ dissipation from sweating. Methyldopa can cause idiosyncratic hyperpyrexia. As men- $\frac{\bar{m}}{\bar{D}}$ tioned earlier, hydrochlorothiazide-induced $\overparen{\otimes}$ hypokalemia could have played a role in the development of rhabdomyolysis ${ }^{9}$ and myocardial ischaemia. ${ }^{10}$

\section{Discussion}

Metabolic acidosis and respiratory alkalosis are the most commonly observed metabolic altera- N tions during heat exhaustion. ${ }^{4}$ Respiratory of alkalosis may result in hypophosphatemia. ${ }^{3}$ This case report is an atypical presentation of $\mathcal{O}$ metabolic alkalosis in association with hypo- o phosphatemia during heat exhaustion, in contrast to commonly reported metabolic acidosis and respiratory alkalosis. ${ }^{3,4}$ The above account reiterates and illustrates the fact that medica- की tions may have major impact on metabolic and $\vec{\bullet}$ electrolyte imbalances in subjects undergoing $\&$ heat exhaustion. It is, therefore, imperative to consider the medications taken by the affected subject while investigating predisposing or aetiologic factors for laboratory abnormalities during heat exhaustion.

\section{Final diagnosis}

Rhabdomyolysis and myocardial ischaemia due to heat exhaustion, plus medicationinduced hypokalemia resulting in metabolic alkalosis (with secondary hypophosphatemia) and increased susceptibility to heat exhaustion.

Keywords: rhabdomyolysis, heat exhaustion, hypophosphatemia, hypokalemia, metabolic alkalosis

in the preparation of this case report.

7 Gardner LI, Talbot NB, Cook CD, Berman $\mathrm{H}$, Uribe The effect of potassium deficiency on carbohydrate metabolism. f Lab Clin Med 1950; 35: 592-602.

8 Blachley J, Long J, Knochel JP. The effect of potassium (K) $\mathbb{D}$ deficiency on resting muscle glycogen $(G)$ content and its ? response to exercise. Clin Res 1974; 39A.

9 Kjellmer I. The potassium ion as a vasodilator during muscular exercise. Acta Physiol Scand 1965; 63: 460-8.

$10 \mathrm{Kew}$ MC, Tucker BK, Bersohn I. The heart in heat stroke. Am Heart f 1969; 77: 324-5. 